\title{
Cutaneous metastasis of colon adenocarcinoma
}

\begin{tabular}{|c|c|}
\hline ABSTRACT & $\begin{array}{l}\text { Skin metastasis originating from colorectal cancer is a rare entity and usually signifies poor prognosis. We present a } \\
\text { case of a } 62 \text {-year-old male patient who presented with a cutaneous metastatic focus on his forehead after five years } \\
\text { of the primary treatment of colon cancer. Complete response from the cutaneous metastasis nodule was achieved } \\
\text { with radiotherapy. The patient is still alive and under a second-line palliative chemotherapy regimen because of the } \\
\text { multiple liver metastases. It is important for physicians to be aware of skin metastasis in patients with an oncology } \\
\text { history. }\end{array}$ \\
\hline & Keywords: Colorectal cancer, skin metastasis, prognosis \\
\hline
\end{tabular}

ORCID IDs of the authors: Y.K 0000-0002-1175-9085; 0.K 0000-0002-6419-6204

Cite this paper as: Kemal Y, Odabaşı EA, Kemal O, Bakırtaş M. Cutaneous metastasis of colon adenocarcinoma. Turk J Surg 201834 (3): 237-239.

'Department of Medical Oncology, Samsun Training and Research Hospital, Samsun, Turkey

${ }^{2}$ Department of Radiation Oncology, Samsun Training and Research Hospital, Samsun, Turkey

${ }^{3}$ Department of

Otorhinolaryngology, Ondokuz Mayıs University School of Medicine, Samsun, Turkey ${ }^{4}$ Department of Pathology, Samsun Training and Research Hospital, Samsun, Turkey

This study was presented at the $21^{\text {st }}$ National Cancer Congress, 22-26 April 2015, Antalya Turkey.

Corresponding Author Özgür Kemal

e-mail:drozgurkemal@gmail.com

Received: 27.07.2015

Accepted: 31.10 .2015

Available Online Date: 03.01.2018

CCopyright 2018

by Turkish Surgical Association

Available online at

www.turkjsurg.com

\section{INTRODUCTION}

Cutaneous metastases arising from an internal malignancy are extremely rare, occurring in $0.001 \%$ of all skin biopsies performed (1). Of these, $6.5 \%$ originate from a primary colorectal cancer (1). If a colon cancer metastases to the skin, it typically presents with a painless flesh-colored nodule or as a mass with occasional ulceration (2). Cutaneous metastasis typically signifies widespread disease with poor prognosis $(3,4)$. The case presented here is of a 62 -year-old male with a large skin metastatic focus on his forehead 5 years after the resection of a colon adenocarcinoma.

\section{CASE PRESENTATION}

This paper is written under the permission of the patient. A 62-year-old male presented at the outpatient clinic with a growing mass on his forehead skin (Figure 1). On clinical examination, a diffuse erythematous multinodular lesion was evident. The patient had a history of colon adenocarcinoma. Five years previously, colonoscopy had been performed due to constipation and an ulcerated mass was found in the sigmoid region. Colonoscopic biopsy revealed adenocarcinoma of the colon, and the patient underwent left hemicolectomy in May 2009. Pathological diagnosis was adenocarcinoma with lymphovascular invasion. No distant metastasis was found. The colon cancer was classified as T3, N1, M0, stage III. Adjuvant 5-fluorouracil-based chemotherapy was administered for 6 months and then follow-up was performed, according to the National Comprehensive Network (NCCN) guidelines.

Five years later, the patient was admitted to hospital with a mass on his forehead. A biopsy specimen was obtained from this nodular mass. On microscopic evaluation, the dermis was seen to have been infiltrated by a number of adenomatous glands, which suggested a metastatic focus of the known colon adenocarcinoma (Figure 2, 3). Abdominal computed tomography also showed multiple liver metastasis. After the restaging work-up, the patient was discussed at a multidisciplinary team meeting and it was decided to administer palliative radiotherapy because of the pain and cosmetic problems. The tumor on his skin was irradiated with daily fractions of $250 \mathrm{cGy}$ with $6 \mathrm{mV}$ energy of electron (Total dose: 60 Gy) to relieve the pain and for palliation and systemic chemotherapy, and Folinic acid, 5-Fluorouracil, Irinotecan (FOLFIRI)+bevacizumab treatment was commenced as the K-RAS test identified a mutation. Complete response from the cutaneous metastatic nodule was achieved with radiotherapy (Figure 4). The patient is currently receiving the second-line palliative chemotherapy regimen [FOLFOX-4 (folinic acid, 5-fluorouracil, oxaliplatin)+bevacizumab] and is in good overall condition. There has been no relapse in the radiotherapy field.

\section{DISCUSSION}

Metastatic skin cancer is defined as skin metastases from visceral cancer, excluding primary skin cancer and hematological malignancies. Skin metastases are rare and the reported incidence range from $1.4 \%$ to $10 \%$ of all visceral cancers $(2,4)$. In males, lung cancer is the leading form of cancer, followed by colorectal, esophageal, and kidney cancers, and in females, the most prevalent is breast cancer followed by colorectal, ovarian, and lung cancers $(5,6)$. Although skin metastases from colorectal 


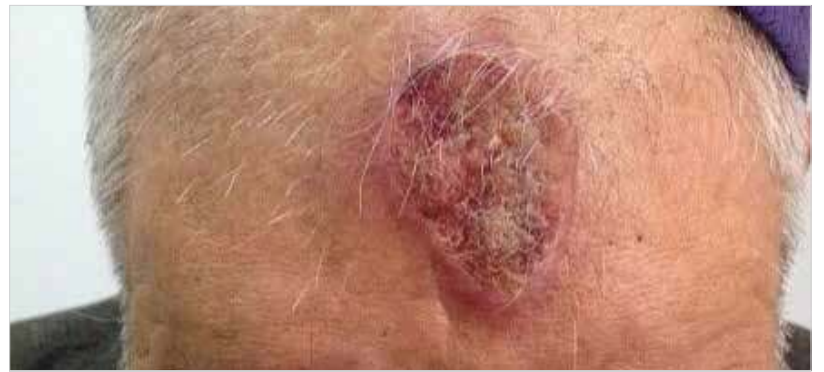

Figure 1. Nodular mass on the forehead

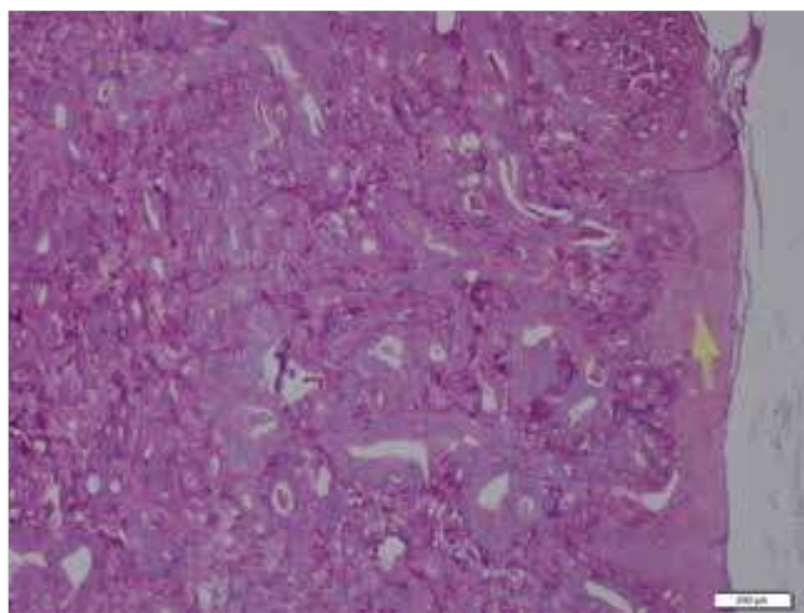

Figure 2. Pathologic section of metastatic foci of the skin: irregular and atypic cells forms abortif adenoidal glands with pseudostratified columnar epithelium; luminal mucus and inflammatory cells. (Hematoxylin and eosin X100)

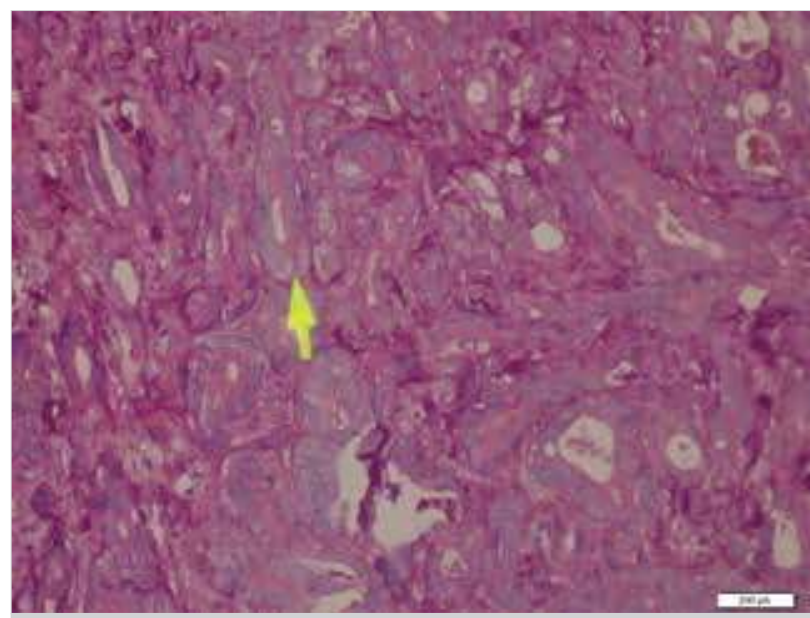

Figure 3. Adenoid glands of the metastatic dermis (Hematoxylin and eosin X 200)

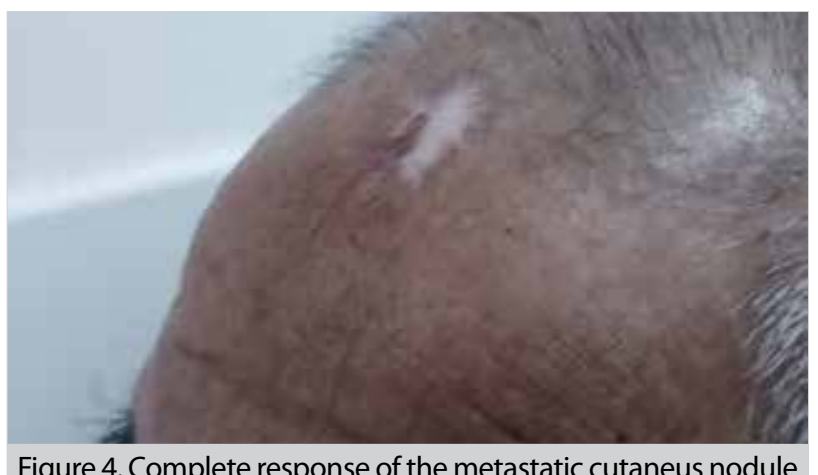

cancer account for nearly $5 \%$, metastases on the face, scalp, and forehead, as seen in this case, are very rare (7). Atalay et al. (8) reported a case series of 8 patients from 263 colorectal cancer patients in 2009. According to this report and other previous reports, if a primary tumor has been previously diagnosed and treated, the onset to the development of cutaneous metastases usually occurs in the first two years (3). This is considered stage IV disease and usually has a poor prognosis.

The exact mechanisms of cutaneous metastasis are still unknown, although several probable ways have been discussed, including direct extension, hematogenous or lymphatic spread, or spread along the ligaments of embryonic origin and implantation of tumor cells (9). It has also been suspected that the vertebral venous plexus plays a role in hematogenous spread to distant sites, as this system may bypass other organs in the circulatory system (10). Despite these hypotheses, the exact mechanisms of metastasis to the skin remain unknown, and the means of metastasis may be different in each patient.

Through various means, metastatic lesions can assume a variety of morphological appearances (11), although the usual presentation is single or multiple nodules of a red color (2). An erythematous ring may be seen around the nodules, as in the current case. They may also resemble epidermal cysts, lipomas, morphea-like plaques, or zona zoster (2). Lookingbill et al. (2) reported in a large study that all the removed skin metastases were nodular. The histological features of metastatic lesions generally mimic the primary tumor, although metastases are generally more anaplastic. Microscopically most skin metastases from colon tumors have a nodular configuration and are located in the dermis, then spreading to the epidermis and subcutaneous tissue (4).

Identification of skin metastasis is a poor prognostic sign and indicates that the disease is widespread. Survival after diagnosis of cutaneous metastasis ranges from 1 to 34 months (2). The current patient is still alive 12 months after presentation with skin metastasis. If possible, wide local excision of the metastatic lesion is recommended. However, reconstruction may often be problematic and palliative options are preferred (11). A multidisciplinary team meeting at our hospital decided on palliative radiotherapy (because of the pain and cosmetic problems) followed by palliative chemotherapy. Interestingly, complete response was achieved after radiotherapy on this skin lesion.

\section{CONCLUSION}

There are very few reports in literature of skin metastasis as the first sign of metastatic disease after five years of the primary treatment of colon cancer. The region of the metastatic site and treatment success with radiotherapy are distinctive characteristics of our case report. It is important for physicians to be aware of skin metastasis in patients with an oncology history who present with cutaneous lesions. Early biopsy may be a good option. The opportunity for local treatment should be given to the patients, especially if the metastasis is located on the face, head, or more visible regions of the body. 
Informed Consent: Written informed consent was obtained from patient who participated in this study.

Peer-review: Externally peer-reviewed.

Author Contributions: Concept - Y.K.; Design -Ö.K.; Supervision - Y.K.; Resource - E.A.O.; Materials - Y.K., E.A.O., Ö.K., M.B.; Data Collection and/ or Processing - Y.K., Ö.K.; Analysis and/or Interpretation Ö.K., Y.K.; Literature Search - Ö.K.; Writing Manuscript - Ö.K., Y.K.; Critical Reviews - Y.K., E.A.O., Ö.K., M.B.

Conflict of Interest: The authors have no conflicts of interest to declare.

Financial Disclosure: The authors declared that this study has received no financial support.

\section{REFERENCES}

1. Saeed S, Keehn CA, Morgan MB. Cutaneous metastasis: a clinical, pathological, and immunohistochemical appraisal. J Cutan Pathol 2004; 31: 419-430. [CrossRef]

2. Lookingbill DP, Spangler N, Helm KF. Cutaneous metastases in patients with metastatic carcinoma: a retrospective study of 4020 patients. J Am Acad Dermatol 1993; 29: 228-236. [CrossRef]

3. Verardino GC, Silva RS, Obadia DL, Gripp AC, Alves Mde F. Rare cutaneous metastasis from a probable basaloid carcinoma of the colon mimicking pyogenic granuloma. An Bras Dermatol 2011; 86: 537-540. [CrossRef]

4. Lookingbill DP, Spangler N, Sexton FM. Skin involvement as the presenting sign of internal carcinoma. A retrospective study of 7316 cancer patients. J Am Acad Dermatol 1990; 22: 19-26. [CrossRef]

5. Brownstein MH, Helwig EB. Patterns of cutaneous metastasis. Arch Dermatol 1972; 105: 862-868. [CrossRef]

6. Sarid D, Wigler N, Gutkin Z, Merimsky O, Leider-Trejo L, Ron IG. Cutaneous and subcutaneous metastases of rectal cancer. Int J Clin Oncol 2004; 9: 202-205. [CrossRef]

7. Reingold I'm. Cutaneous metastases from intestinal carcinoma. Cancer 1966; 16: 162.

8. Atalay C, Yılmaz KB. Cutaneous metastases in colorectal cancer. Balkan Med J 2009; 26: 312-316.

9. Eichinger J, George B, Myhand R. Cutaneous metastatic rectal carcinoma masquerading as herpes zoster. South Med J 2011; 104: 233-235. [CrossRef]

10. Kleyn CE, Lai-Cheong JE, Bell HK. Cutaneous manifestations of internal malignancy: diagnosis and management. Am J Clin Dermatol 2006; 7: 71-84. [CrossRef]

11. Gu Y, Tang R, Gong DQ, Qian YL. Reconstruction of the abdominal wall by using a combination of the human acellular dermal matrix implant and an interpositional omentum flap after extensive tumor resection in patients with abdominal wall neoplasm: a preliminary result. World J Gastroenterol 2008; 14: 752757. [CrossRef] 